\title{
Ausencias, visibilizaciones y valoración del arte y las culturas de los pueblos indígenas en la revista Aisthesis
}

\author{
Margarita Alvarado Pérez \\ Instituto de Estética, Facultad de Filosofía, Pontificia Universidad Católica de Chile. \\ malvarap@uc.cl
}

Aisthesis, Revista Chilena de Investigaciones Estéticas, en sus cincuenta años de trayectoria, ha constituido un espacio donde se han expresado los más diversos temas y problemáticas en relación al arte y la cultura en sus diferentes ámbitos de manifestación, pero siempre bajo una perspectiva donde la estética ha ocupado un lugar fundamental.

Ya desde los comienzos de esta publicación se puede observar que el teatro (Aisthesis $\left.\mathrm{n}^{\circ} 1,1966\right)$; la crítica de arte $\left(\mathrm{n}^{\circ} 2,1967\right)$; la novela $\left(\mathrm{n}^{\circ} 3,1968\right)$; la arquitectura ( $\left.\mathrm{n}^{\circ} 4,1969\right)$; la poesía $\left(\mathrm{n}^{\circ} 5,1970\right)$; y la educación por el arte $\left(\mathrm{n}^{\circ} 6,1971\right.$ y n $\mathrm{n}^{\circ} 7$, 1972), constituyen temas que merecen la publicación de números especiales. En estos primeros diez años de la revista, se abordan, desde distintas perspectivas teóricas y metodológicas, las problemáticas que presentan cada uno de estos campos expresivos, demostrando tempranamente uno de sus principales objetivos: desarrollar diálogos interdisciplinarios a nivel nacional e internacional, con la filosofía como referente esencial, pero teniendo en cuenta relaciones con diferentes áreas de las humanidades y las ciencias sociales.

En los años siguientes, durante la década de los ochenta, esta heterogeneidad se manifiesta en la publicación de números misceláneos donde diversos autores abordan temas que abarcan campos como la literatura, las artes visuales y la teoría estética en combinación con otros números que contienen estudios monográficos sobre diversos temas, como por ejemplo aquellos titulados "Estética y Folklore" (Aisthesis n 15, 1983; $\left.\mathrm{n}^{\circ} 16,1984 ; \mathrm{n}^{\circ} 20,1987 ; \mathrm{n}^{\circ} 22,1989\right)$, donde se despliegan importantes reflexiones que instalan una perspectiva claramente estética sobre este ámbito tan complejo de nuestras manifestaciones culturales. 
Esta modalidad de abordaje casi monográfico sobre un tema se afianzará en épocas posteriores -desde fines de la década de los 2000, cuando se comienzan a publicar dos números por año-, llegando a constituir los llamados Dossier. En ellos, se incluyen conjuntos de trabajos, separados del cuerpo de artículos de la revista, que están dedicados a campos específicos de las artes y las ciencias sociales, y que han sido escritos por profesionales especialmente convocados para que expongan sus puntos de vista, marcos teóricos y metodologías de investigación y reflexión, configurando así una mirada transversal sobre diversas expresiones (Aisthesis $\mathrm{n}^{\circ} 41$, julio 2007, "Estética y ciudad latinoamericana"; n ${ }^{\circ} 42$, diciembre 2007, "Estética y cuerpo"; n 43, julio 2008, "Estética y danza"; ${ }^{\circ} 44$, diciembre 2008, "Estética y teatro"; n 45, julio 2009, "Problemas de representación"; n 46, diciembre 2009, "Fotografía y alteridad"; $\mathrm{n}^{\circ} 47$, julio 2010, "Cine y política en Chile"; $\mathrm{n}^{\circ} 48$, diciembre 2010, "Cine y política en Latinoamérica”; ${ }^{\circ}$ 52, diciembre 2012, "Estética y Técnica”; y n 54, diciembre 2013, "Escrituras de Infancia”). De este modo, se puede apreciar cómo esta variedad de temáticas, articuladas bajo una escritura analítica y reflexiva sobre diferentes sistemas de sentido, tradiciones culturales y modalidades de expresión, revela una clara voluntad de exponer y difundir en las páginas de esta revista aquellos abordajes e investigaciones que abarcan problemáticas vinculadas con expresiones visuales, sonoras y orales, así como manifestaciones que comprometen diversas instancias de producción simbólica.

Si consideramos las palabras pronunciadas por el doctor César Zamorano en la presentación de los números 58 y 59 de Aisthesis, llevada a cabo en enero del año 2016 en el Instituto de Estética (PUC), en cuanto a que es en "las revistas donde podemos observar cómo y cuáles son las relaciones que constituyen un campo intelectual, entendido como un espacio social, relativamente autónomo de producción de bienes simbólicos", podemos decir, sin temor a equivocarnos, que los cincuenta años de trayectoria de Aisthesis revelan de manera inequívoca la amplitud de relaciones entre distintos campos de significación propios de ámbitos que atañen a la cultura y sus complejas tramas de significaciones.

Sin embargo, a pesar de su amplitud teórica y epistemológica, se observan en esta revista algunas ausencias respecto de ciertas culturas y poblaciones de nuestro país y nuestro continente. Nos referimos específicamente a los pueblos originarios, también llamados pueblos indígenas, que habitaron América desde mucho antes de la llegada de los conquistadores hispanos, franceses e ingleses y que aún siguen existiendo, formando parte de nuestras sociedades actuales, a pesar de los cambios y transformaciones a los que fueron sometidos durante los procesos de independencia ocurridos durante el siglo XIX.

Gracias a su amplitud cronológica y a una extraordinaria diversidad cultural e identitaria, los pueblos indígenas de América han dejado -y aún mantienen- un legado de artefactos, costumbres, creencias y tradiciones que hoy forman parte de nuestro patrimonio cultural. Esta herencia demuestra su acabado conocimiento de la natu- 
raleza, el domino de recursos y materias primas, de complejas soluciones técnicas y, sobre todo, de delicados y sofisticados sistemas de sentido con sus respectivos códigos estéticos y expresivos. Todo este universo de formas, colores y texturas, modalidades sonoras y visuales, así como de tradiciones, mitos y relatos orales, han sido abordados por investigadores y estudiosos de las ciencias sociales, intentando conocer y profundizar en las concepciones y formas de vida de estos pueblos del pasado y el presente.

Arqueólogos, historiados, antropólogos y por supuesto estetas, han trabajado por muchos años -sobre todo en Chile- para establecer cronologías, comprender las relaciones sociales y políticas presentes en estas sociedades y develar las concepciones estéticas y formales subyacentes en sus producciones materiales. Esta profusión de trabajos en el campo de las ciencias sociales de alguna manera ha estado ausente de las páginas de la revista Aisthesis en estos cincuenta años de historia; sin embargo, al revisar una trayectoria tan extensa de publicación, es posible observar que sí existen ciertas visibilizaciones de problemáticas sobre culturas indígenas específicas.

Así, a los diez años de la aparición del primer número de la revista, en la sección Documentos del número 10, encontramos una primera mención en cuanto a los pueblos originarios, en la recopilación titulada "Bibliografía y piezas originales de la Isla de Pascua existentes en la Sede Central de la Congregación de los ss.cc. PicpusRoma”, de la profesora Camila Laureani. En este trabajo, se expone un catastro de un importante material del pueblo Rapanui conservado en una institución de una congregación religiosa en la ciudad de Roma. Más que un análisis o problematización sobre aspectos estéticos o históricos de la cultura de esta isla ubicada en medio del océano Pacífico, se visibiliza un conjunto de textos y objetos como un patrimonio para ser difundido. En el número siguiente, el número 11, del año 1978, la profesora Lauriani publica, también en la sección Documentos, un trabajo titulado "Isla de Pascua", en donde despliega su conocimiento sobre esta cultura, contribuyendo así a la valoración de sus manifestaciones materiales y sociales. Su mirada de historiadora del arte se completa con dos artículos posteriores dedicados también a la cultura Rapanui, "Acerca de la historia de Isla de Pascua" (n 13, 1979) y "Los ahu de Isla de Pascua" ( $\left.\mathrm{n}^{\circ} 14,1982\right)$. En estos textos, a través de la contextualización histórica y la reflexión acerca de una manifestación arquitectónica tan particular de este territorio insular, Lauriani instala una clara valoración de ciertas manifestaciones a las que se les atribuye la condición de arte producido por un pueblo indígena específico.

Es importante tener en cuenta que durante la década de los sesenta y comienzos de los años setenta, la presencia de los pueblos indígenas no siempre era reconocida y mucho menos valoradas sus expresiones más allá que como mera artesanía, desconociendo que sus producciones materiales y sus manifestaciones culturales son el resultado de complejos sistemas de sentido que contienen códigos estéticos y simbólicos de extraordinaria riqueza y sofisticación. Es también en estos años donde comienzan a afianzarse diversos estudios antropológicos sobre diferentes pueblos indígenas, como por ejemplos los pioneros trabajos de María Ester Grebe en relación con el mundo 
mapuche y aymara, y las dedicadas etnografías realizadas por Anne Chapmann en el mundo de los habitantes australes, poniendo en evidencia que grupos yamana, kawesqar y selk'man todavía habitan en Tierra del Fuego. Conjuntamente, los estudios arqueológicos se sistematizan con la creación de la Licenciatura en Arqueología de la Universidad de Chile (1968); además, se afianza el papel de los coleccionistas privados como Sergio Larraín y Ricardo Claro, quienes constituyen enormes colecciones de objetos que décadas más tarde serán la base sobre la que se organizarán el Museo Chileno de Arte Pecolombino, a comienzo de los ochenta, y el Museo Andino, a comienzos de los años 2000. En esta época, el mundo indígena tiene una particular presencia en ciertas expresiones visuales, especialmente en la fotografía, que en su género documental registra una realidad social a menudo convulsionada. En estas representaciones, muchas veces las particularidades étnicas se visualizan escasamente, potenciando una imagen de una realidad campesina más que étnica, sobre todo en relación con el pueblo mapuche.

En este contexto, la escasa visibilización del indígena como sujeto protagonista de procesos históricos, sociales y culturales comienza a revertirse lentamente. Estudios y producciones posicionan la cultura material como un elemento fundamental de estos procesos, caracterizando lo indígena como parte de vestigios que deben ser descubiertos y descritos. De alguna manera, este objetivo lo cumplen los trabajos de Camila Laurriani publicados en Aisthesis en sus primeros diez años de aparición, en cuanto estos aportes implicarán la puesta en escena de nuevas valoraciones de las producciones del mundo indígena.

Un punto de inflexión importante para la visibilización de este mundo indígena en la revista Aisthesis se va a producir a partir de la publicación de un número titulado "Estética y Folklore" ( $\left.\mathrm{n}^{\circ} 15,1983\right)$, donde se inaugura un proceso de incorporación de ciertas identidades culturales, pero como parte de lo que se denomina folklore, entendido en su acepción más amplia, es decir, un conjunto de creencias, prácticas y costumbres de un pueblo o una cultura, a los cuales se les asigna una tradicionalidad que se expresa en el campo de la oralidad, la musicalidad y los artefactos de la cultura material. Se inaugura así la búsqueda de otras expresiones, otras estéticas, bajo una mirada focalizada en una alteridad cultural que busca incorporar una pluralidad de voces, modos de ver y de hacer para establecer el folklore como "arte", donde lo indígena, justamente como parte de una alteridad, se manifestará de manera implícita, pero no por eso menos visible. Los principios que modelan este nuevo acercamiento estético se pueden encontrar en uno de los primeros artículos de este número, titulado "Notas para una Estética del Folklore", donde Fidel Sepúlveda plantea:

Desde esta perspectiva [en la cultura occidental] ha emanado una actitud discriminatoria, a lo sumo condescendiente, para un tipo de manifestaciones originadas desde otra vertiente de lo humano: la alteridad tradicional. Tales expresiones serán vistas como normalmente inferiores. Es más bien inconcebible que en esos niveles pudiera producirse algo 'perfecto'. Sin embargo, y a medida 
que la antropología ha ido reivindicando la legitimidad de la pluralidad cultural, se está reconociendo el valor de las expresiones tradicionales, y con ello, las del folklore. La reivindicación argumentada del folklore como arte, no obstante, no constituye un capítulo importante en la bibliografía iberoamericana (13-4).

Y si bien, como dice Sepúlveda, una reivindicación del folklore como arte no constituye un aspecto fundamental de la producción de textos en Iberoamérica, a partir de este número, Aisthesis se va a constituir una plataforma fundamental para la construcción y el despliegue de un pensamiento reflexivo sobre estos temas. Junto a este primer número, se suman otros tres editados en otros años ( ${ }^{\circ} 16,1983$, "Estética y Folklore II"; n 20, 1987, "Estética y Folklore III"; y n²2, 1989, "Estética y Folklore IV"), en donde, gracias a la diversidad de perspectivas y autores, se completa una amplia mirada sobre el folklore como eje fundamental, pero teniendo en consideración diversos temas, como la etnoestética (María Ester Grebe, Carlos González); aspectos sobre la cultura y sus manifestaciones (Viola Román, Marcelo Arnold, Fernando Slater); y otras expresiones artísticas, como el cuento (Regina Valdés, Jaime Blume) y la música (Gastón Soublette, Fidel Sepúlveda). En este caleidoscopio teórico y metodológico, donde autores especialistas en antropología, filosofía, musicología y literatura reflexionan sobre las problemáticas del folklore y sus diversos sistemas de sentido, lo indígena como una alteridad cultural aparece a veces de forma implícita y otras se visibiliza en la descripción de ejemplos y casos de estudio.

En estos años, los números dedicados al folklore se complementan con otros volúmenes que rondan temáticas complementarias y donde el reconocimiento del arte indígena como una producción colmada de sentido y complejidad estética se hace mucho más visible y se valora definitivamente. Así, el mito como una expresión cultural propia de lo americano se trabaja en el número titulado "Estética y Mito" ( $\mathrm{n}^{\circ}$ 17, año 1984), donde Jorge Montoya posiciona la temática en su trascendencia: "parece que no ha habido cultura que no haya gestado mitos, leyendas o alegorías como maneras de poder responder a todas las inquietudes en torno a la existencia" (11). Además, se estudia su presencia en un recorrido que comprende la Isla de Chiloé en el sur de Chile (Jaime Blume, Viola Román, Fernando Slater) y la Isla de Pascua (Camila Lauriani), y se incluye también una reflexión sobre la vinculaciones del mito con una expresión visual tan compleja como el cine (Luis Cecereu).

En cuanto a la visibilización y valoración del arte de los pueblos indígena, mención especial merece el número titulado "Estética e identidad cultural" (n²7, 1994), donde junto a varios autores que tratan diversos aspectos de esta problemática, cuatro especialista de las culturas indígenas (Pedro Miras, Ricardo Salas, Carlos González y Jaime Blume) reflexionan sobre las culturas precolombinas y actuales considerando especialmente sus producciones religiosas y materiales, bajo el supuesto que "sólo una mirada nueva de índole estética que recupere sin prejuicios nuestras raíces precolombinas puede permitirnos acceder a una mirada no esquizofrénica de nosotros mismos" (82). 
Es notable ver que esta necesidad de considerar las expresiones del mundo indígena bajo una mirada estética coincide con una lenta pero permanente emergencia del mundo y el movimiento indígena a nivel americano y sobre todo chileno. Ya para la década de los ochenta y comienzo de los noventa, los pueblos indígenas han entrado en complejos procesos de re-etnificación, es decir, de recuperación de identidades, cultura y presencia sobre todo en escenarios urbanos como Santiago y otras ciudades importantes del centro y sur de Chile. Un hecho que potencia estos procesos es la promulgación, en 1993, de la llamada ley indígena ( $\left.\mathrm{N}^{\circ} 19.253\right)$, en la cual, según el documento emitido por la Corporación Nacional de Desarrollo Indígena, "El Estado reconoce como principales etnias indígenas de Chile a: la Mapuche, Aimara, Rapa Nui o Pascuenses, la de las comunidades Atacameñas, Quechuas, Collas y Diaguita del norte del país, las comunidades Kawashkar o Alacalufe y Yámana o Yagán de los canales australes". En este mismo texto, se declara también que "El Estado valora su existencia por ser parte esencial de las raíces de la Nación chilena, así como su integridad y desarrollo, de acuerdo a sus costumbres y valores".

De esta manera, se articula un escenario que facilita la instalación de sujetos específicos pertenecientes a etnias determinadas que, bajo iniciativas políticas, culturales y reivindicativas, inician potentes procesos de reinstalación y recuperación de sus expresiones culturales, tradiciones y costumbres, donde el patrimonio artefactual, tanto en el ámbito de lo cotidiano como del ritual, toma un papel fundamental. En este contexto, la aparición del número "Estética y Mito" no deja de tener importancia, porque posiciona una reflexión que visualiza y valora expresiones específicas del arte y la cultura de los pueblos originarios.

Para fines de los años noventa y principios de los años 2000, la revista Aisthesis va a publicar números misceláneos combinados con algunos Dossier temáticos que ya se analizaban a comienzos de este artículo. De esta manera, la visibilización de las producciones de los pueblos indígenas estará siempre combinada con una reflexión teórica y de casos de estudio que incluyen ámbitos propios de la literatura, las artes visuales y la música, intercalados con artículos que abordan temas de religiosidad y ritualidades, producciones simbólicas indígenas o del mundo popular. Dentro de estos artículos, destacan un conjunto de trabajos publicados en diversos años que abordan problemáticas asociadas al pueblo mapuche. El primero de ellos es "Imágenes de diversidad y consenso: la cosmovisión Mapuche a través de tres Machis", de Mariela Bacigalupo ( $\left.{ }^{\circ} 28,1995\right)$, donde se analizan temas tan delicados como la institución chamánica de la machi dentro del mundo mapuche, incluyendo sus manifestaciones espirituales y materiales. El segundo es "Vida, muerte y paisaje en los bosques templados. Un acercamiento a la estética del paisaje de la región del Calafquén", de Margarita Alvarado ( $\left.n^{\circ} 33,2000\right)$, donde se analizan las relaciones entre las concepciones del pueblo mapuche sobre el entorno que habita y su mirada sobre la vida y la muerte. Y el tercero y último es "Rescate de una construcción mapuche no conocida”, de Carlos González y Hugo Rosati (n³9, 2006), quienes bajo una pers- 
pectiva interdisciplinaria analizan un sitio con vestigios de las antiguas ocupaciones mapuche de la época de la conquista hispana.

Para poner fin a este recorrido que ha permitido reflexionar acera de las ausencias, visibilizaciones y valoración del arte y las culturas indígenas de los pueblos originarios en la revista Aisthesis, es importante detenerse en un dossier titulado "Fotografía y Alteridad" ( $\mathrm{n}^{\circ} 46$, diciembre 2009), en el cual ocho autores, entre los cuales se cuentan antropólogos, historiadores del arte y estetas, realizan un recorrido sobre las representaciones visuales fotográficas de indígenas americanos y sus implicancias sociales, políticas, históricas y estéticas, poniendo en evidencia de qué manera, bajo este sistema representacional, se han ido construyendo diversos sujetos y realidades culturales.

En esta época de transición de un siglo al otro, donde cada vez con más fuerza se va abriendo paso la necesidad de considerar que somos una sociedad multicultural, en la cual el mundo indígena no siempre ha sido valorado por sus producciones artísticas y simbólicas, estos artículos y este dossier, aunque todavía de manera aislada, se instalan en un medio académico y de investigación como un intento de reconocimiento de ciertas complejidades estéticas, culturales y políticas. No debemos olvidar que ya en esta primera década de los años 2000, el movimiento indígena ha transitado un largo camino de luchas, organización e instalación de reivindicaciones, consolidando su presencia en los más amplios ámbitos de nuestra sociedad. Alguna iniciativas han ayudado en estos procesos, como la firma del Convenio 169 de la oIT (Organización Internacional del Trabajo) sobre Pueblos Indígenas y Tribales en Países Independientes, que aporta una nueva legislación para el reconocimiento y respeto de la diversidad cultural y étnica. Adoptado en Ginebra el 27 de junio de 1989 y ratificado por nuestro país en septiembre del año 2008, establece "el deber para el Estado de Chile de consultar las medidas legislativas y administrativas susceptibles de afectar directamente a los pueblos originarios, estableciendo procedimientos apropiados de consulta a los pueblos interesados, de buena fe y con la finalidad de llegar a un acuerdo o lograr el consentimiento acerca de las medidas propuestas". Junto con lo anterior, "regula además materias relacionadas con la costumbre y derecho consuetudinario de los pueblos originarios, establece ciertos principios acerca del uso y transferencia de las tierras indígenas y recursos naturales, junto con su traslado o relocalización [...] se refiere a la conservación de su cultura y a las medidas que permitan garantizar una educación en todos los niveles" (s/p).

Dado las fortalezas del movimiento indígena en la actualidad, es evidente que ha logrado cambiar las percepciones que se tienen respecto de los pueblos originario, así como también la misma sociedad se ha ido abriendo a considerar al mundo indígena como parte importante de un destino compartido. Bajo estas coordenadas, debemos enfrentar los nuevos desafíos que nos plantean estos tiempos de la posmodernidad, donde se tensiona definitivamente el concepto de "arte" que estamos aplicando a las producciones indígenas. 
En este contexto, Aisthesis tiene como desafío fundamental la consolidación de una reflexión académica sobre la disciplina estética aplicada al mundo de la cultura material e inmaterial de los pueblos indígenas, donde se hace evidente la existencia de otros sistemas simbólicos y otros códigos estéticos que es necesario estudiar, develar y comprender, siempre en vinculación interdisciplinaria con un vasto espectro de las ciencias sociales y las humanidades y, por supuesto, con la filosofía como un referente genealógico principal. Solo de esta manera se podrá concretar una concepción y una práctica intercultural en una sociedad multiétnica, donde el arte y la cultura de los pueblos originarios debe llegar a ser totalmente visibilizado y justamente valorado. 